\title{
Safety and efficacy of soluble guanylate cyclase stimulators in patients with heart failure: A systematic review and meta- analysis.
}

Waqas Ullah

Abington Jefferson Health

Maryam Mukhtar

Rawalpindi Institute of Cardiology

Aws Al-Mukhtar

Imperial College London

Rehan Saeed

Abinothqhis deffersagiteflealth works at: https://jdc.jefferson.edu/abingtonfp

irgapt Bfatigoardiology Commons phingtens defferserkepltow access to this document benefits you

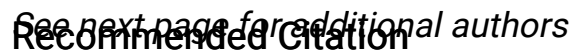

Ullah, Waqas; Mukhtar, Maryam; Al-Mukhtar, Aws; Saeed, Rehan; Boigon, Margot; Haas, Donald; and Rame, Eduardo., "Safety and efficacy of soluble guanylate cyclase stimulators in patients with heart failure: A systematic review and meta-analysis." (2020). Abington Jefferson Health Papers. Paper 53.

https://jdc.jefferson.edu/abingtonfp/53

This Article is brought to you for free and open access by the Jefferson Digital Commons. The Jefferson Digital Commons is a service of Thomas Jefferson University's Center for Teaching and Learning (CTL). The Commons is a showcase for Jefferson books and journals, peer-reviewed scholarly publications, unique historical collections from the University archives, and teaching tools. The Jefferson Digital Commons allows researchers and interested readers anywhere in the world to learn about and keep up to date with Jefferson scholarship. This article has been accepted for inclusion in Abington Jefferson Health Papers by an authorized administrator of the Jefferson Digital Commons. For more information, please contact: JeffersonDigitalCommons@jefferson.edu. 


\section{Authors}

Waqas Ullah, Maryam Mukhtar, Aws Al-Mukhtar, Rehan Saeed, Margot Boigon, Donald Haas, and Eduardo. Rame 


\section{World Journa
Cardiology}

World J Cardiol 2020 October 26; 12(10): 475-512

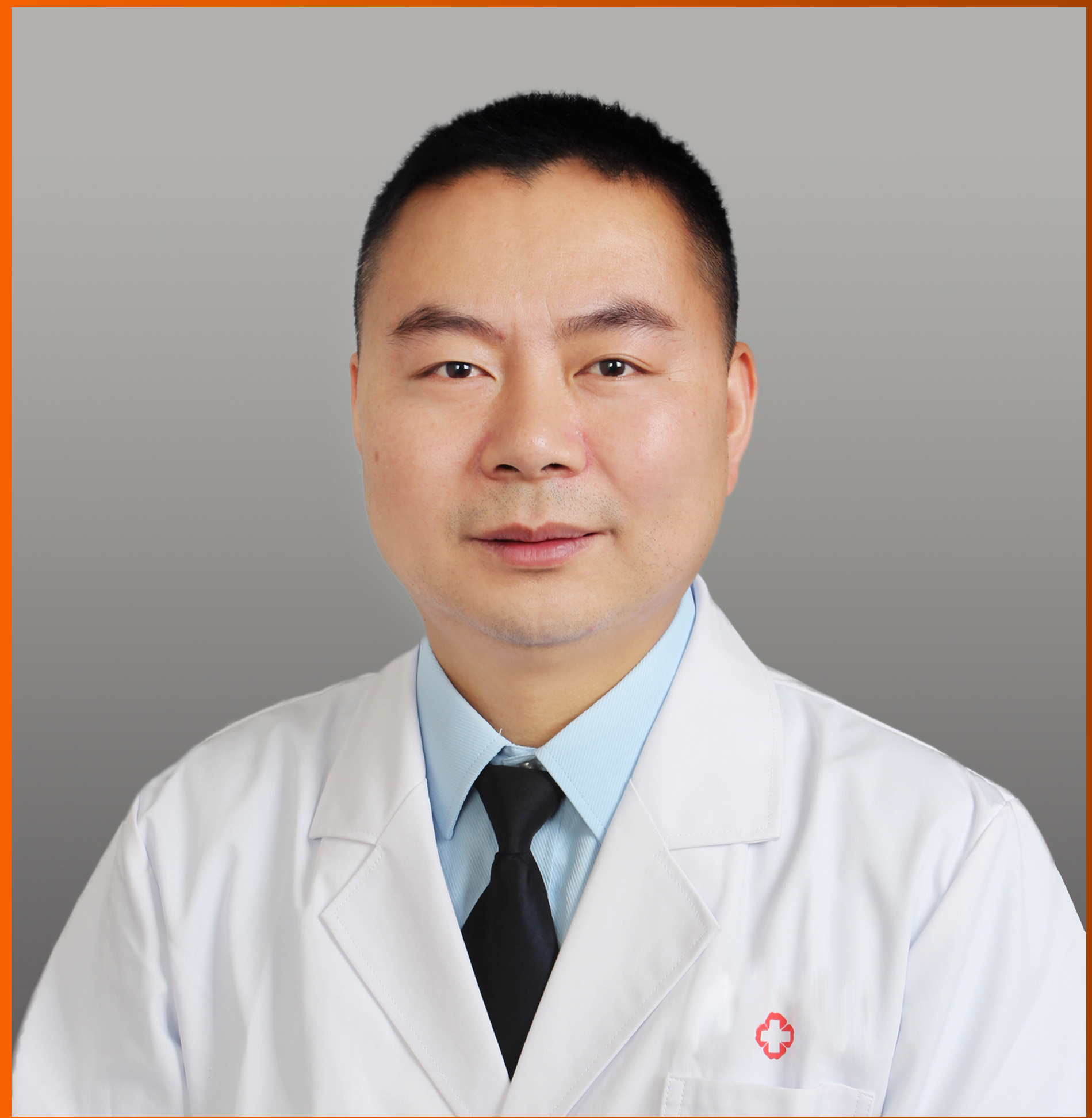




\section{WI T $\mathcal{C}$ World Journal of Cardiology}

\section{Contents}

Monthly Volume 12 Number 10 October 26, 2020

\section{MINIREVIEWS}

475 Electronic cigarettes - myocardial infarction, hemodynamic compromise during pregnancy, and systolic and diastolic dysfunction: Minireview

Vajdi B, Tuktamyshov R

\section{ORIGINAL ARTICLE}

Retrospective Study

484 Upper body peripherally inserted central catheter in pediatric single ventricle patients

Kaipa S, Mastropietro CW, Bhai H, Lutfi R, Friedman ML, Yabrodi M

492 Risk score for predicting abdominal complications after coronary artery bypass grafting

Belov DV, Garbuzenko DV, Abramovskikh KA, Arefyev NO

\section{META-ANALYSIS}

501 Safety and efficacy of soluble guanylate cyclase stimulators in patients with heart failure: A systematic review and meta-analysis

Ullah W, Mukhtar M, Al-Mukhtar A, Saeed R, Boigon M, Haas D, Rame E 


\section{Contents}

\section{ABOUT COVER}

Editorial board member of World Journal of Cardiology, Dr. Dai is a Distinguished Cardiovascular Doctor at the Yan'an Affiliated Hospital of Kunming Medical University (China). After receiving his Bachelor's degree from Kunming Medical University in 2006, he continued his postgraduate training at the same institute, receiving a Master's degree in 2009 and a PhD in 2015. He quickly rose to Deputy Chief Physician in the Cardiology Division of Yan'an Affiliated Hospital, in 2016. His ongoing research interests involve the application of evidence-based medicine in cardiovascular diseases, particularly to study coronary heart disease, heart failure, congenital heart disease, and pulmonary artery hypertension. (L-Editor: Filipodia)

\section{AIMS AND SCOPE}

The primary aim of World Journal of Cardiology (WJC, World J Cardiol) is to provide scholars and readers from various fields of cardiology with a platform to publish high-quality basic and clinical research articles and communicate their research findings online.

WJC mainly publishes articles reporting research results and findings obtained in the field of cardiology and covering a wide range of topics including acute coronary syndromes, aneurysm, angina, arrhythmias, atherosclerosis, atrial fibrillation, cardiomyopathy, congenital heart disease, coronary artery disease, heart failure, hypertension, imaging, infection, myocardial infarction, pathology, peripheral vessels, public health, Raynaud's syndrome, stroke, thrombosis, and valvular disease.

\section{INDEXING / ABSTRACTING}

The WJC is now abstracted and indexed in Emerging Sources Citation Index (Web of Science), PubMed, PubMed Central, Scopus, China National Knowledge Infrastructure (CNKI), China Science and Technology Journal Database (CSTJ), and Superstar Journals Database.

\section{RESPONSIBLE EDITORS FOR THIS ISSUE}

Production Editor: Jia-Hui Li; Production Department Director: Xiang Li; Editorial Office Director: Jia-Ping Yan.

NAME OF JOURNAL
World Journal of Cardiology
ISSN
ISSN $1949-8462$ (online)
LAUNCH DATE
December 31,2009
FREQUENCY
Monthly
EDITORS-IN-CHIEF
Ramdas G Pai, Dimitrios Tousoulis, Marco Matteo Ciccone
EDITORIAL BOARD MEMBERS
https://www.wjgnet.com/1949-8462/editorialboard.htm
PUBLICATION DATE
October 26,2020
COPYRIGHT
C 2020 Baishideng Publishing Group Inc
(1)

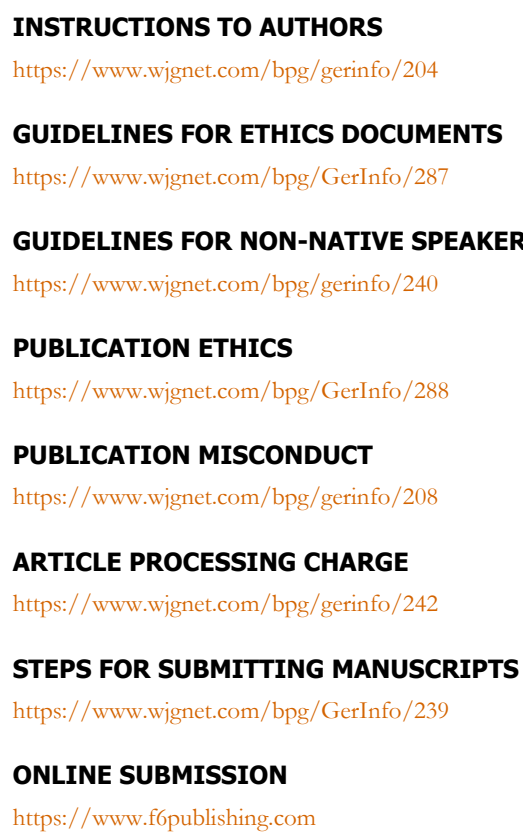

https://www.f6publishing.com 


\title{
W $\mathcal{C} C$ World Journal of Cardiology
}

\section{Safety and efficacy of soluble guanylate cyclase stimulators in patients with heart failure: A systematic review and meta-analysis}

\author{
Waqas Ullah, Maryam Mukhtar, Aws Al-Mukhtar, Rehan Saeed, Margot Boigon, Donald Haas, Eduardo Rame
}

ORCID number: Waqas Ullah 00000002-4850-0309; Maryam Mukhtar 0000-0003-4870-3269; Aws AlMukhtar 0000-0002-8257-3448; Rehan Saeed 0000-0001-9099-4202; Margot Boigon 0000-0002-35317089; Donald Haas 0000-0002-86444205; Eduardo Rame 0000-0002$5552-2055$.

Author contributions: Ullah W contributed to the conceptualization, writing, data analysis; Al-Mukhtar A contributed to the data curation; Mukhtar M contributed to the investigation; Al-Mukhtar A and Mukhtar M wrote the original draft; Saeed R and Ullah W contributed to the review and editing; Ullah W and Boigon M contributed to the project administration; Haas D and Rame E contributed to the supervision and validation.

Conflict-of-interest statement: The authors deny any conflict of interest.

PRISMA 2009 Checklist statement: The authors have read the PRISMA 2009 Checklist, and the manuscript was prepared and revised according to the PRISMA 2009 Checklist.

Open-Access: This article is an open-access article that was selected by an in-house editor and
Waqas Ullah, Rehan Saeed, Margot Boigon, Donald Haas, Department of Internal Medicine, Abington Jefferson Health, Abington, PA 19001, United States

Maryam Mukhtar, Department of Cardiology, Rawalpindi Institute of Cardiology, Rawalpindi 44000, Punjab, Pakistan

Aws AI-Mukhtar, Department of Surgery and Cancer, Imperial College London, London SW7 2AZ, United Kingdom

Eduardo Rame, Department of Cardiology, Thomas Jefferson University, Philadelphia, PA 19001, United States

Corresponding author: Waqas Ullah, MD, Doctor, Department of Internal Medicine, Abington Jefferson Health, 1200 Old York Road, Abington, PA 19001, United States. waqasullah.dr@gmail.com

\section{Abstract \\ BACKGROUND}

The utility of novel oral soluble guanylate cyclase (sGC) stimulators (vericiguat and riociguat), in patients with reduced or preserved ejection fraction heart failure (HFrEF/HFpEF) is currently unclear.

\section{AIM}

To determine the efficacy and safety of sGC stimulators in HF patients.

\section{METHODS}

Multiple databases were searched to identify relevant randomized controlled trials (RCTs). Data on the safety and efficacy of sGC stimulators were compared using relative risk ratio (RR) on a random effect model.

\section{RESULTS}

Six RCTs, comprising 5604 patients (2801 in sGC stimulator group and 2803 placebo group) were included. The primary endpoint (a composite of cardiovascular mortality and first HF-related hospitalization) was significantly reduced in patients receiving sGC stimulators compared to placebo [RR 0.92, 95\% confidence interval $(\mathrm{CI}): 0.85-0.99, P=0.02]$. The incidence of total HF-related hospitalizations were also lower in sGC group (RR 0.91, 95\% CI: 0.86-0.96, $P=$ 0.0009), however, sGC stimulators had no impact on all-cause mortality (RR 0.96, 95\%CI: 0.86-1.07, $P=0.45$ ) or cardiovascular mortality (RR 0.94, 95\%CI: 0.83-1.06, 
fully peer-reviewed by external reviewers. It is distributed in accordance with the Creative Commons Attribution NonCommercial (CC BY-NC 4.0) license, which permits others to distribute, remix, adapt, build upon this work non-commercially, and license their derivative works on different terms, provided the original work is properly cited and the use is non-commercial. See: htt p://creativecommons.org/licenses /by-nc/4.0/

Manuscript source: Unsolicited manuscript

Received: May 7, 2020

Peer-review started: May 7, 2020

First decision: May 24, 2020

Revised: May 31, 2020

Accepted: September 11, 2020

Article in press: September 11, 2020

Published online: October 26, 2020

P-Reviewer: Ciccone MM

S-Editor: Yan JP

L-Editor: A

P-Editor: Li JH
$P=0.29$ ). The overall safety endpoint (a composite of hypotension and syncope) was also similar between the two groups (RR 1.50, 95\% CI: $0.93-2.42, P=0.10$ ). By contrast, a stratified subgroup analysis adjusted by type of $\mathrm{sGC}$ stimulator and HF (vericiguat $v$ s riociguat and HFrEF vs HFpEF) showed near identical rates for all safety and efficacy endpoints between the two groups at a mean follow-up of 19 wk. For the primary composite endpoint, the number needed to treat was 35 , the number needed to harm was 44 .

\section{CONCLUSION}

The use of vericiguat and riociguat in conjunction with standard HF therapy, shows no benefit in terms of decreasing HF-related hospitalizations or mortality.

Key Words: Vericiguat; Riociguat; Soluble guanylate cyclase; Heart failure; Guanylate cyclase stimulator

CThe Author(s) 2020. Published by Baishideng Publishing Group Inc. All rights reserved.

Core Tip: Recently soluble guanylate cyclase (sGC) stimulators (vericiguat and riociguat) have emerged as a novel treatment for heart failure with reduced or preserved ejection fraction. Data published in literature revealed no additional benefits to guideline-based medical therapy in reducing incidence of heart failure hospitalization and mortality with sGC stimulator use. Large scale studies are required to determine the efficacy of sGC stimulators in patients with heart failure.

Citation: Ullah W, Mukhtar M, Al-Mukhtar A, Saeed R, Boigon M, Haas D, Rame E. Safety and efficacy of soluble guanylate cyclase stimulators in patients with heart failure: A systematic review and meta-analysis. World J Cardiol 2020; 12(10): 501-512

URL: https://www.wjgnet.com/1949-8462/full/v12/i10/501.htm

DOI: https://dx.doi.org/10.4330/wjc.v12.i10.501

\section{INTRODUCTION}

There are an estimated 6.5 million adults in the United States suffering from heart failure (HF) with the disease accounting for nearly 1 in every 8 deaths ${ }^{[1]}$ Approximately 1 million $^{[2,3]}$ HF-related hospitalizations (HHF) occur annually, accounting ${ }^{[4]}$ for over 6.5 million hospital days and $\$ 37.2$ billion in costs every year ${ }^{[1]}$. This economic burden has risen dramatically over the past two decades, with the increasing prevalence of risk factors for HF adding to new cases and better therapies adding to increased life expectancy among HF patients ${ }^{[1]}$.

Despite traditional pharmacologic management with beta-blockers, angiotensinconverting-enzyme inhibitors (ACEI) and mineralocorticoid receptor antagonists to reduce HF exacerbations and mitigate clinical progression, overall prognosis remains dismal ${ }^{[2]}$. This has led researchers to target alternative pathways involved in the pathogenesis of HF, with promising research focusing on soluble guanylate cyclase (sGC) and the natriuretic peptide system (NPS) ${ }^{[3,4]}$.

Both pathways influence myocardial perfusion and ventricular function through their common second messenger: Cyclic guanosine monophosphate (cGMP). The therapeutic augmentation of NPS with a combination angiotensin receptor-neprilysin inhibitor (sacubitril) has proven to be immensely beneficial, to the extent that the pioneering PARADIGM trial was halted early given the clear benefits in terms reducing mortality [risk ratio (RR) $0.84,95 \%$ confidence interval (CI): $0.76-0.93, P<$ $0.001]$ and hospitalization (by $21 \%, P<0.001$ ) compared to ACEI alone ${ }^{[5]}$. However, the use of conventional vasodilators (nitrites and nitrates) to achieve soluble GC activation has met with more mixed results, with the development of tolerance, hypotension and failure of treatment being reported ${ }^{[]]}$. These discouraging findings have been attributed to a relative deficiency of SGC due to reduced nitric oxide (NO) bioavailability and endothelial dysfunction in HF leading to impaired cyclic GMP generation ${ }^{[7]}$.

Novel sGC stimulators (vericiguat and riociguat) have shown advances over traditional vasodilators ${ }^{[6]}$, by augmenting the cGMP signaling pathway, independent 
of $\mathrm{NO}$ and enhancing the effect of endogenous $\mathrm{NO}^{[2,8]}$. In contrast to the conventional therapeutic approach of antagonizing counterregulatory neurohormonal pathways, such as by phosphodiesterase inhibitors, or by addition of exogenous NO, sGC stimulators sensitize soluble GC to endogenous $\mathrm{NO}$, thereby potentially having more efficacy for HF treatment ${ }^{[9]}$.

In this regard, multiple clinical trials have attempted to explore the utility of vericiguat and riociguat in patients with $\mathrm{HF}^{[2,8]}$. The VICTORIA (vericiguat Global Study in Subjects with Heart Failure with Reduced Ejection Fraction) trial recently established that vericiguat in patients with HFrEF can reduce the risk of cardiovascular mortality and HF-related hospitalizations ${ }^{[2]}$. These findings, however, stand in contrast to previous trials that have not shown any consistent benefit with sGC stimulators. The ambiguity of current literature and the absence of any definite large-scale studies to determine the true merits of sGC stimulators in patients with HF, motivated us to perform this meta-analysis.

\section{MATERIALS AND METHODS}

\section{Search strategy and data extraction}

The MEDLINE (PubMed, Ovid), Embase, Clinicaltrials.org and Cochrane databases were queried with various combinations of medical subject headings $(\mathrm{MeSH})$ to identify relevant articles. There were no language or time restrictions placed. Backward snowballing was performed to retrieve unidentified studies that were missed on the initial search. The MeSH used included two subsets: One for HF using the terms like "heart failure," "HFrEF," "HFpEF," "CHF," "cardiac failure," and the other for sGC using "guanylate cyclase stimulators," "sGC," "vericiguat," and "riociguat." The two subsets of MeSH were combined in a 1:1 combination using Boolean operators. Results from all possible combinations were downloaded into an EndNote library. All randomized control trials (RCT) until March 31, 2020, comparing the safety and efficacy of sGC in HF were evaluated for inclusion.

Patients with HFrEF and HFpEF [New York Heart Association (NYHA) class II-IV], on optimal guideline-based medical therapy requiring hospitalization or outpatient intravenous (IV) diuretics, were included in this study. Patients requiring IV inotropic support, in acute decompensated HF or requiring mechanical device support were excluded, so were patients using suboptimal doses of vericiguat $(<10 \mathrm{mg}$ daily) or riociguat $(<2 \mathrm{mg}$ daily), nitrates, alternative sGC stimulators or PDE inhibitors.

The primary efficacy endpoint was a composite of the first hospitalization for HF and death from cardiovascular causes. The secondary efficacy endpoints were the components of the primary outcome, total HF-related hospitalizations, cardiovascular and all-cause mortality. Safety endpoints included anemia, hypotension, syncope, and a composite of the later two. A detailed search map and definition of outcomes are given in the Supplementary Appendix.

\section{Data and quality analysis}

The statistical analysis was performed using the Cochran-Mantel-Haenszel test on a random-effect model to calculate RR for the dichotomous outcomes of RCTs. The probability value of $P<0.05$ was considered statistically significant. The "test for overall effect" was reported as the $\mathrm{z}$ value corroborating the inference from the $95 \% \mathrm{CI}$. Subgroup analysis based on the choice of sGC stimulator and type of HF was also performed. Higgins I-squared $\left(I^{2}\right)$ statistical model was used to assess variations in outcomes of the included studies. $I^{2}$ less than $40 \%$ corresponded to low heterogeneity. Depending upon the strength of evidence for heterogeneity ( $P$ value from the chisquare $\chi^{2}$ analysis), $I^{2}$ of 41 to $74 \%$ indicated moderate $(P \geq 0.05)$ or moderate to severe ( $P \leq 0.05)$ and $I^{2}$ of $75 \%$ or higher suggested substantial heterogeneity. Publication bias was illustrated graphically using a funnel plot. The methodological quality assessment of the included RCTs was performed using the Cochrane collaboration tool for the systematic review and meta-analysis, where each study was screened for five different types of bias (selection, performance, detection, attrition, and reporting bias). All statistical analysis was performed using the Cochrane Review Manager (RevMan) version 5.3 .

\section{Quality of the included studies}

The overall quality of the included RCTs was high (Figure 1). Due to adequate randomization and allocation concealment, the risk of selection bias was low. The risk of performance and detection bias were reduced with appropriate blinding of 
A

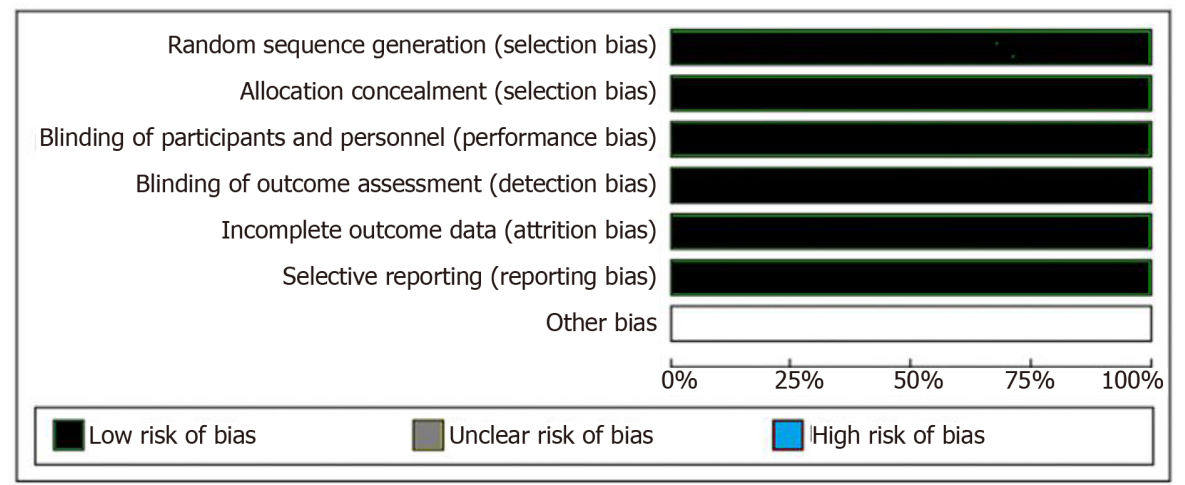

B

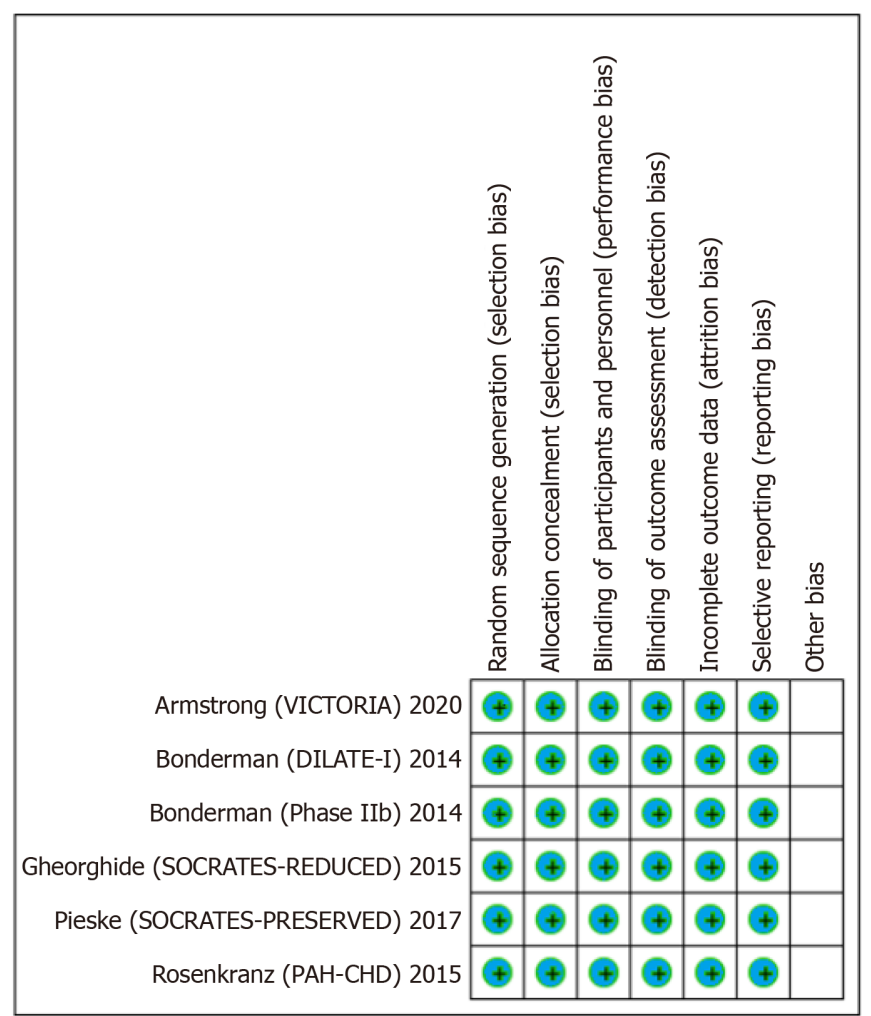

Figure 1 Summary and detailed methodological quality of the included studies. A: Summary of the included studies; B: Detailed methodological quality of the included studies.

participants and outcomes, respectively. Similarly, reporting bias across all studies was decreased due to an adequate description of the study results. The fact that most RCTs used an "intention to treat model" or had a minimal loss at follow-up, the risk of attrition bias was low.

\section{RESULTS}

\section{Search results and study characteristics}

The initial search revealed 1905 articles. After the removal of irrelevant and duplicate items, 43 studies were selected for full-text review. Of these, 37 articles were excluded based on our selection criteria, 6 articles (all RCTs) qualified for quantitative analysis ${ }^{[2,8,10-13]}$. The Preferred Reporting Items for Systematic Reviews and MetaAnalyses (PRISMA) flow diagram is shown in Figure 2.

A total of 5604 patients, 2801 in the sGC stimulator group, and 2803 in the placebo group were included. The mean age of patients receiving sGC stimulator was 64 and for the placebo group 62 years; comprising 59\% and 57\% male patients, respectively. Three of the included trials used vericiguat $(1.25,2.5,5$, or $10 \mathrm{mg})$, and three RCTs used riociguat $(0.5,1$, or $2 \mathrm{mg})$ in the experimental arm. Baseline characteristics of 


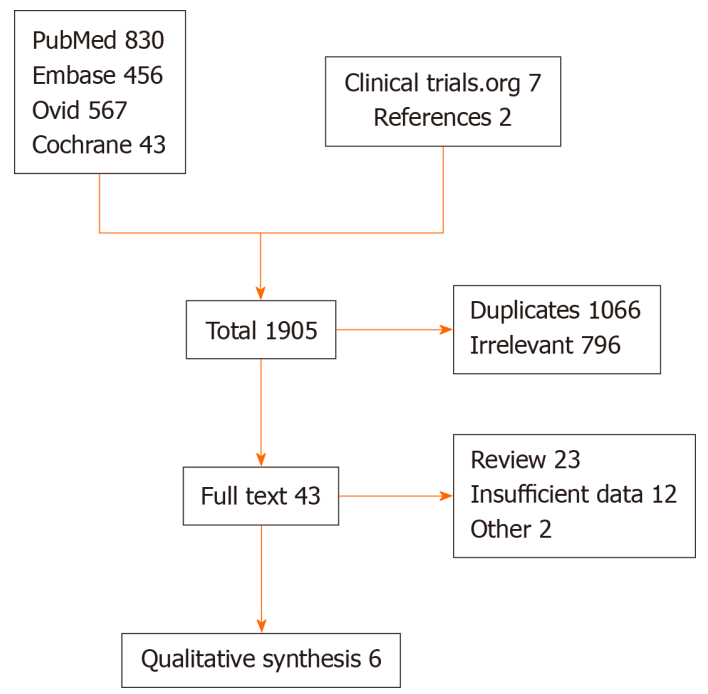

Figure 2 Flow diagram of the included studies showing reasons for exclusion.

treatment and placebo groups were comparable. Use of the concomitant guidelinedirected HF medical therapy was also balanced between the two groups. The VICTORIA and the (soluble guanylate cyclase stimulator in heart failure patients with preserved and reduced EF) SOCRATES trials used vericiguat in HFrEF patients. These patients had a mean EF of $29 \%$ and NYHA class III-IV. The median baseline Nterminal pro-B-type natriuretic peptide (NT-proBNP) levels were $2816 \mathrm{pg} / \mathrm{mL}$ and $3076 \mathrm{pg} / \mathrm{mL}$, respectively. The SOCRATES-PRESERVED trial used the Kansas City cardiomyopathy questionnaire-clinical summary score to gauge symptomatic improvement in the HFpEF population. The DILATE-1 (acute hemodynamic effects of riociguat in patients with pulmonary hypertension associated with diastolic heart failure) investigated riociguat in the HFpEF population. The PAH-CHD (pulmonary arterial hypertension after correction of congenital heart disease) trial included younger patients with a mean $38 \pm 15$ years. The PAH-CHD and the LEPHT (left ventricular systolic dysfunction associated with pulmonary hypertension) had $100 \%$ and $97 \%$ of HF patients with NYHA II-III, respectively. The overall follow-up duration ranged from 12-43 wk, with a mean follow up of $19 \mathrm{wk}$. The detailed baseline characteristics, inclusion criteria, and definitions of outcomes are given in Supplementary Tables 1-3, respectively.

\section{Pooled analysis of overall studies}

Pooled efficacy endpoints: Four studies comprising 5530 patients (2752 sGC stimulator and 2778 placebo) compared the primary composite endpoint (cardiovascular mortality plus first-time hospitalization) between the sGC stimulators and the control group. At a mean follow-up of 21-wk, a significantly lower rate of the primary endpoint was obtained with the use of sGC stimulator in HF patients (RR 0.92, 95\% CI: 0.85-0.99, $P=0.02$ ) (Figure 3A). Similarly, compared to placebo, the rate of total HF-related hospitalizations was significantly lower (RR 0.91, 95\% CI: 0.86-0.96, $P=$ 0.000 .9 ) in patients on sGC stimulators. However, the incidence of cardiovascular and all-cause mortality remained identical in both groups at a mean follow up of 19-mo (RR 0.94, 95\% CI: 0.83-1.06, $P=0.29$ and RR 0.96, 95\% CI: $0.86-1.07, P=0.45$, respectively) (Figure 3B). Six studies consisting of 5604 patients (2801 sGC stimulator and 2803 placebo) contributed to the later comparison (Figure 4). There was no heterogeneity among the outcomes of the included studies $\left(I^{2}=0 \%\right)$.

Pooled safety endpoints: Six studies comprising 5596 patients (2793 sGC stimulator and 2803 placebo) were used to calculate the incidence of net adverse events of clinical interest (NAECI) (a composite of hypotension and syncope). The rate of NAECI was 1.5 times higher but statistically non-significant in patients receiving sGC stimulators compared to placebo (RR 1.50, 95\%CI: 0.93-2.41, $P=0.10$ ) (Figure 3B). The incidence of hypotension (RR 1.47, 95\% CI: 0.93-2.33, $P=0.10$ ) and syncope (RR 1.18, 95 CI: 0.90$1.55, P=0.24$ ) were also numerically higher with the use of sGC stimulator use by $47 \%$ and $18 \%$ respectively; however, none of these differences reach the level of statistical significance. The incidence of anemia was significantly higher in sGC group (RR 1.33, 95\% CI: 1.08-1.64, $P=0.007)$. There was minimal heterogeneity among the studies 
A

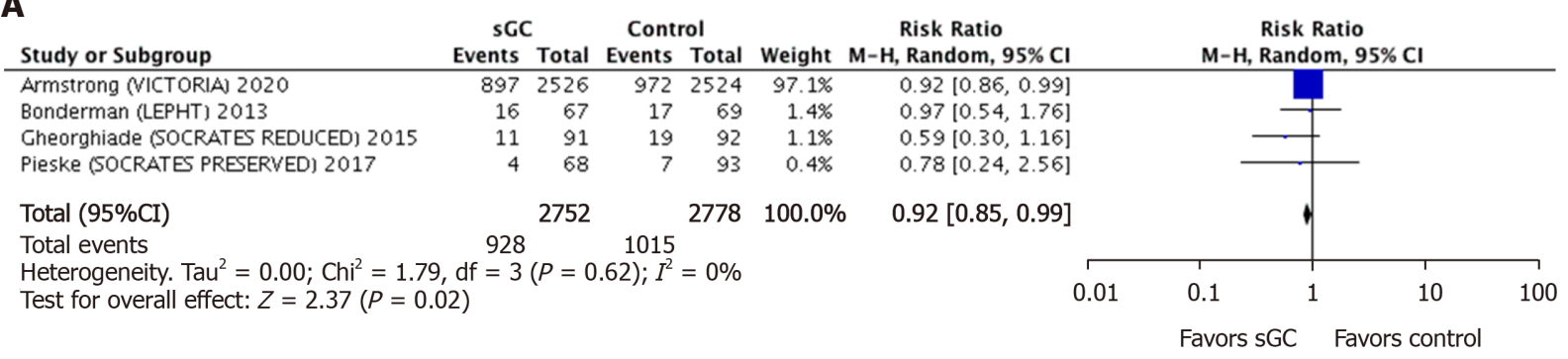

B

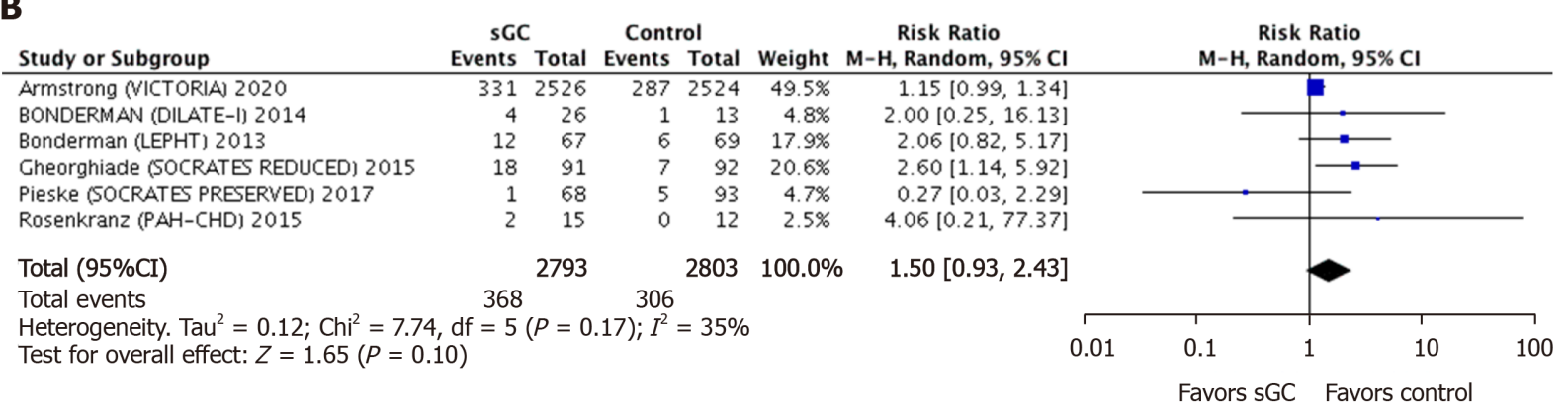

Figure 3 Forest plot for the primary composite endpoint overall side-effects showing an individual and pooled risk ratio for randomized controlled trials comparing soluble guanylate cyclase stimulators to control. A: Pooled composite endpoint; B: Overall side-effects. The pooled risk ratio (RR) with $95 \%$ confidence interval $(\mathrm{Cl})$ were calculated using random-effects models. Weight refers to the contribution of each study to the overall pooled estimate of treatment effect. Each square and horizontal line denotes the point estimate and $95 \% \mathrm{Cl}$ for each trial's RR, respectively. The diamonds signify the pooled $\mathrm{RR}$; the diamond's centre denotes the point estimate and width denotes the $95 \% \mathrm{Cl}$. Cl: Confidence interval; sGC: Soluble guanylate cyclase.

comparing NAECI and hypotension $\left(I^{2}=35 \%\right.$ and $I^{2}=20 \%$, respectively) .

Net clinical benefit: The overall number needed to treat (NNT) for the primary composite endpoint by adding vericiguat to the standard guideline-directed HF therapy was 35 (95\% CI: 18.7-332.2). The overall number needed to harm (NNH) for NAECI was 44 (95\%CI: 25.2-180). The net clinical benefit (NCB) was 9, indicating futility. The overall NNT to prevent one death due to any-cause was 142 (95\% CI: 36.374.2) and to prevent one death from cardiovascular cause was 111 (95\% CI: 35.3-96.7). None of the NNT values was statistically significant, as evidenced by the cross-over of its $\mathrm{CI}$ with the $\mathrm{NNH}$.

\section{Subgroup sensitivity analysis}

A stratified analysis of prespecified subgroups adjusted on the type of HF (HFrEF and HFpEF) and choice of experimental regimen (vericiguat and riociguat) showed significant deviation from the pooled results. Two studies comprising 5233 patients (2616 sGC stimulator and 2617 placebo) contributed to the comparison of vericiguat and placebo agents in HFrEF patients. In contrast to the pooled results, there was no significant difference in the incidence of primary composite endpoint between patients receiving vericiguat and placebo for HFrEF (RR 0.84, 95\% CI: 0.58-1.21, $P=0.24$ ). Similarly, the rate of primary composite endpoint remained identical across patients on placebo and those receiving riociguat for $\mathrm{HFrEF}$ (RR 0.97, 95\% CI: 0.54-1.76, $P=$ 0.92) or HFpEF (RR 0.78, 95\%CI: 0.24-2.56, $P=0.68$ ) (Supplementary Figure 1). Compared to placebo, there was no significant difference in the rate of total HF-related hospitalizations across HFrEF patients receiving vericiguat (RR 0.84, 95\% CI: 0.60-1.20, $P=0.34)$ or riociguat (RR $0.97,95 \% \mathrm{CI}: 0.54-1.76, P=0.92)$ and HFpEF patients on riociguat (RR 0.68, 95\% CI: 0.18-2.64, $P=0.58$ ) (Supplementary Figure 2).

The incidence of all-cause mortality stratified by the type of sGC stimulators or type of HF mirrored the overall results. A similar rate of mortality was obtained between patients on placebo $v$ s those on vericiguat (RR 0.96, 95\% CI: 0.86-1.07, $P=0.43$ ) or riociguat (RR 1.97, 95\% CI: 0.32-12.16, $P=0.46$ ) (Supplementary Figure 3). Both HFrEF (5369 patients, 2648 sGC stimulator and 2685 placebo) and HFpEF (200 patients, 94 sGC stimulator and 106 placebo group) followed the pooled results of all-cause mortality, showing a similar incidence of mortality between the two groups (RR 0.96, 95\% CI: $0.86-1.07, P=0.44$ and RR $1.45,95 \%$ CI: 018-11.54, $P=0.73$, respectively) ( Supplementary Figure 4). Sensitivity analysis by the exclusion of PAH-CHD study also 
A

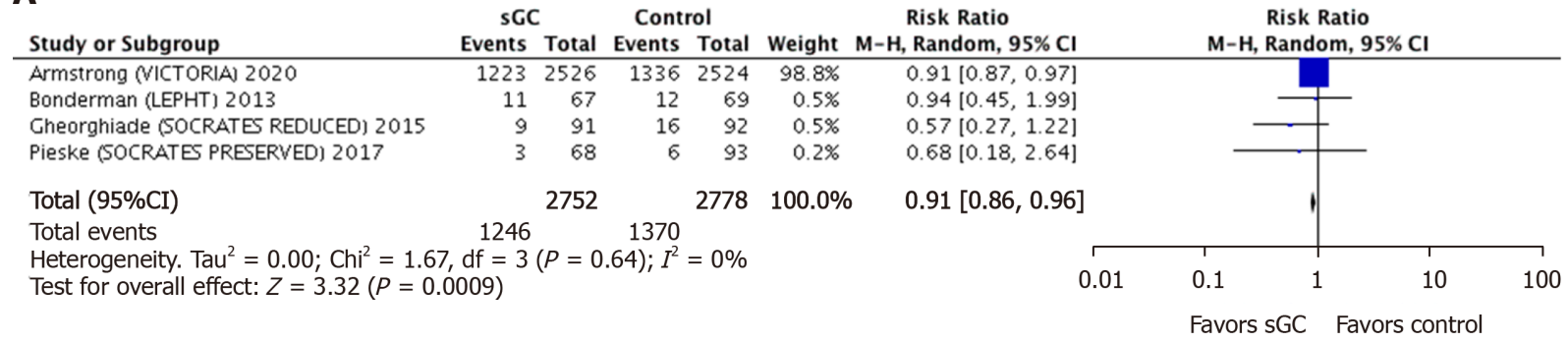

B

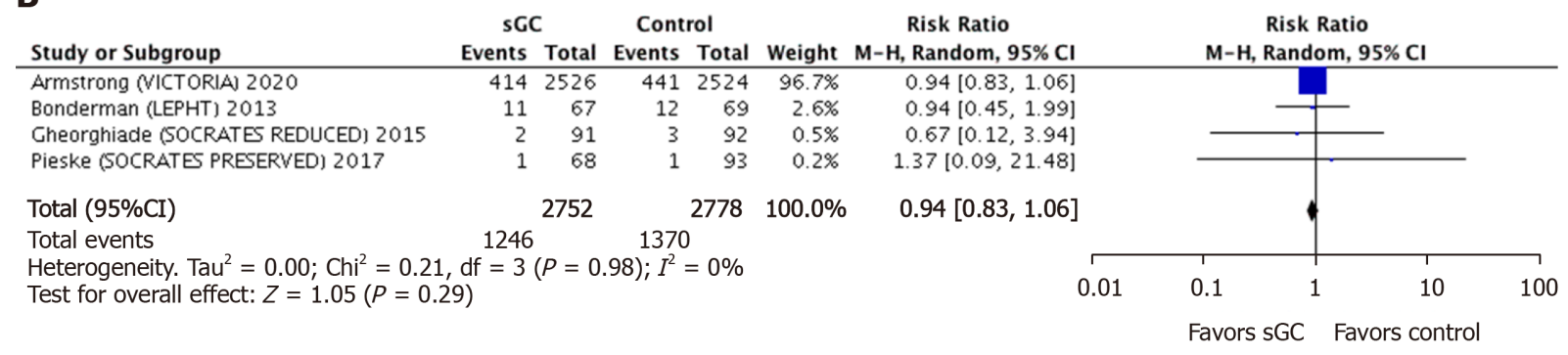

\section{C}

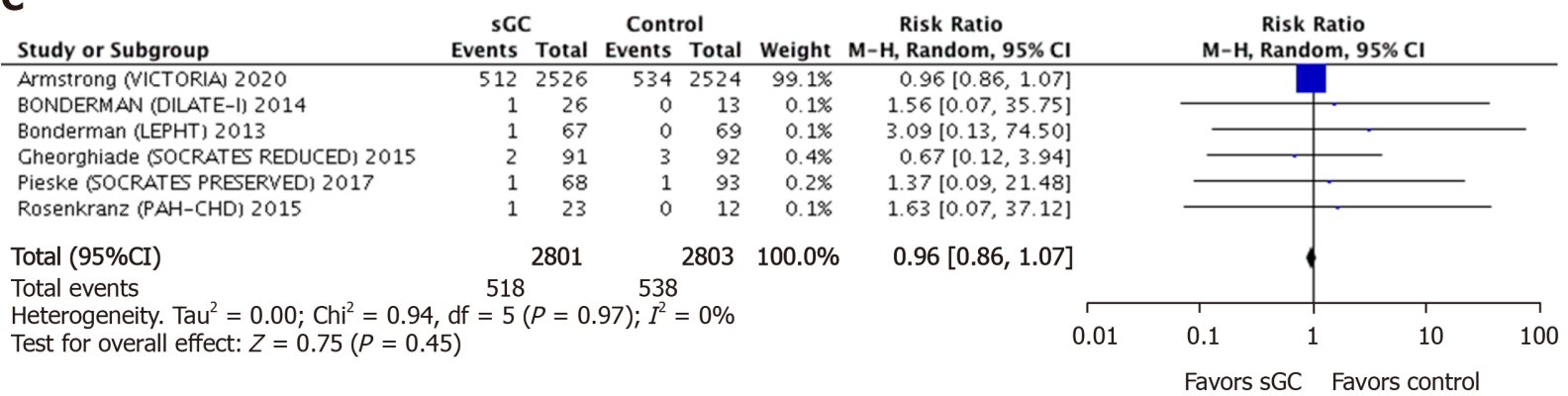

Figure 4 Forest plot for hospitalizations, cardiovascular and all-cause mortality showing an individual and pooled risk ratio for randomized controlled trials comparing soluble guanylate cyclase stimulators to control. A: Hospitalizations; B: Cardiovascular; C: All-cause mortality. Cl: Confidence interval; sGC: Soluble guanylate cyclase.

did not alter the results of pooled analysis (RR $0.96,95 \% \mathrm{CI}: 0.86-1.07, P=0.45)($ Supplementary Figure 5).

\section{Publication bias}

The funnel plot showed asymmetry, indicating the possibility of publication bias. (Figure 5) The vertical axis of the plot used standard error to estimate the sample size of the study, plotting large population studies on top and smaller at the bottom. The horizontal spread reflected the power and effect size of the included studies. One can argue that it is difficult to differentiate between "findings by chance" and "real asymmetry," as only six articles were assessed for potential publication bias. As pointed by Sterne et $a l^{[14]}$. in a study of fewer than ten articles, it is difficult to ascertain publication bias.

\section{DISCUSSION}

To our knowledge, this is the largest study performed to assess the safety and efficacy of novel sGC stimulators (vericiguat and riociguat) in patients with HF. The results were drawn from 6 RCTs, comprising 5604 patients. In the combined analysis, among patients with high-risk HF (NYHA class II-IV), the addition of sGC stimulators to current guideline-based medical therapy showed a modest decrease in risk of the primary composite endpoint (first HF hospitalization plus cardiovascular death) by $8 \%$. With a similar decrease in HF-related total hospitalization by $9 \%$. However, these benefits were attenuated when the pooled results were matched based on the type of $\mathrm{HF}$ and choice of sGC stimulator. Neither vericiguat nor riociguat groups reached the threshold of statistical significance when the efficacy endpoints (hospitalization and 


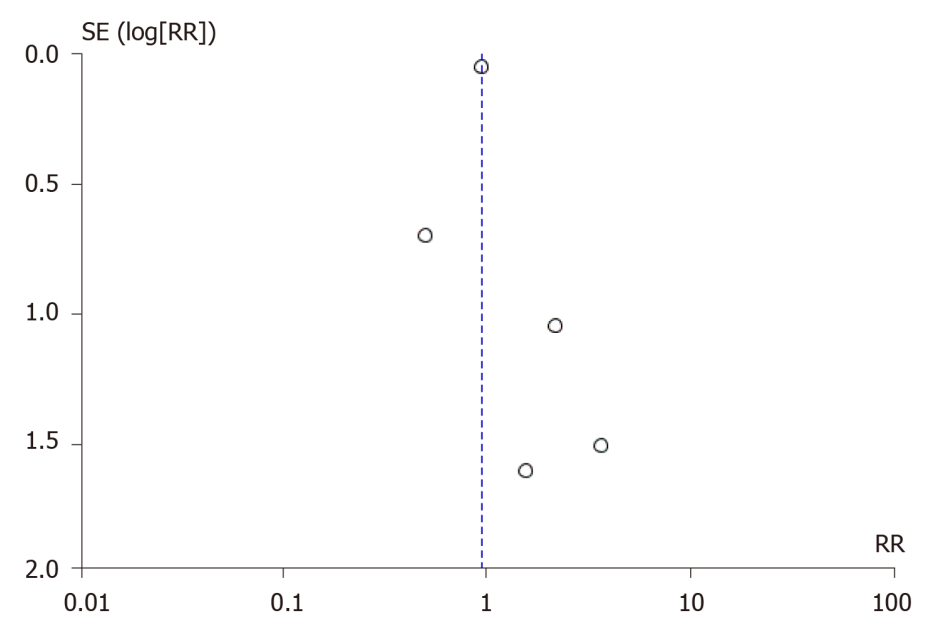

Figure 5 Funnel plot showing possible publication bias. RR: Risk ratio.

death) were stratified by HFrEF and HFpEF. Similarly, compared to the control group, both vericiguat and riociguat failed to lower the incidence of cardiovascular or allcause mortality, irrespective of the type of HF or duration of follow-up. Moreover, the incidence of NAECI and its components (hypotension and syncope) in the intervention group were 1.5 times higher than the placebo group. Briefly, our analysis did not show the same positive findings seen in the recent VICTORIA trial and highlight the ambiguity in the use of sGC stimulators, until more definitive evidence is available ( Supplementary Figure 6).

It is interesting to compare our combined results with all included RCTs. The SOCRATES-PRESERVED and the SOCRATES-REDUCED trials used vericiguat in patients with HFpEF and HFrEF, respectively ${ }^{[10,11]}$. These trials were primarily designed to determine the optimal dose and tolerability of vericiguat. While on pooled analysis, the relative difference in the NT-proBNP levels was identical, the SOCRATES-REDUCED did show a significant dose-response relationship. Compared to placebo, a higher vericiguat dose of $10 \mathrm{mg}$ was associated with greater reductions in NT-proBNP $(P=0.02)$ and significant improvement in LVEF $(+1.5 \% v s+3.7 \%, P=0.02)$ at 3 mo follow-up ${ }^{[11]}$. Similarly, the SOCRATES-PRESERVED trial showed a substantial improvement in the functional and symptomatic status of the HFpEF patients (increase in KCCQ-CSS by more than 5 points) on the $10 \mathrm{mg}$ dose of vericiguat at 3 $\mathrm{mo}^{[10]}$. Both SOCRATES-PRESERVED and REDUCED trials used surrogate markers of disease severity and were relatively underpowered to gauge hard clinical outcomes (mortality and hospitalizations).

Three of the included RCTs compared the merits of riociguat against a placebo in both HFrEF and HFpEF patients. The PATENT-1 (the pulmonary arterial hypertension sGC-stimulator trial-1) and its long-term extension study PATENT-2 were unique in terms of inclusion criteria and assessment of outcomes. Riociguat was found to be associated with a decrease in the mean NT-proBNP levels, improved 6-minute walking distance (6MWD) and pulmonary vascular resistance (PVR) in patients with PAH$\mathrm{CHD}^{[12]}$. Both LEPHT and DILATE-1 trials demonstrated a significant increase in the stroke volume $(P=0.001$ and $P=0.04)$ in their respective HFrEF and HFpEF patient populations. However, there was no significant decrease in the mean pulmonary arterial pressure (PAP), the primary endpoint, even at the maximally tolerated dose of riociguat $(2 \mathrm{mg})^{[8,13]}$. These trials were also underpowered to assess major clinical endpoints and had variability in dose-response outcomes, limiting their utility.

The more contemporary VICTORIA trial was adequately powered and specifically designed to measure clinically relevant outcomes ${ }^{[2]}$. The trial used a cox-regressionmodel to calculate a sample size of 5050 patients, who were hospitalized with the diagnosis of HFrEF. Both vericiguat and placebo groups in the trial were appropriately matched, minimizing ascertainment bias, but had a high rate of noncompliance and loss to follow-up. At a median follow-up of $10 \mathrm{mo}, 24 \%$ of the vericiguat and $22 \%$ of the placebo arm had discontinued the trial regimen. While this amount of nonadherence was anticipated and an "intention to treat model" was used to reduce its impact on the overall results, the pooled difference in the primary composite endpoint was modest (RR 0.90,95\% CI: 0.82-0.98, $P=0.02$ ). The incidence of cardiovascular mortality was near identical in the vericiguat and placebo groups $(12.9 \%$ vs $13.9 \%, P=0.83)$, indicating that the primary outcome was driven by the 
lower rate of HF-related hospitalization in the vericiguat group $38.3 \%$ vs $42.4 \%, P=$ $0.02)^{[2]}$. By contrast, our pooled analysis of vericiguat in HFrEF population showed no inter-group difference in both the incidence of the primary composite $(P=0.34)$, cardiovascular mortality $(P=0.29)$, and total HF-related hospitalizations $(P=0.34)$. Nonetheless, mirroring our pooled results, the VICTORIA trial showed no significant difference in the incidence of all-cause mortality between vericiguat and the placebo groups $(20.3 \%$ vs $21.2 \%, P=0.38)$. This underscores that the lower hospitalization rate in the vericiguat arm did not translate into clinical survival benefits. Together, these findings call for caution while interpreting the findings of the VICTORIA trial.

The present meta-analysis sought to address the overall discrepancies by systematically adjusting the definition of primary composite outcome and by excluding patients on the suboptimal dose of sGC stimulators. By design, our study prevents the influence of both known and unknown confounding factors due to the inclusion of high-quality studies. Our study showed no clinical benefits of sGC stimulator in terms of reducing mortality or HF-related hospitalization when the overall outcomes were stratified by type of $\mathrm{HF}$ and regimen of trial medication. These findings contrast with the most contemporary VICTORIA trial, which showed a decrease in the incidence of HF-related total hospitalizations and death from cardiovascular causes. Also unique was a demonstration of the consistent ineffectiveness of vericiguat and riociguat to reduce all-cause mortality across all included trials. Moreover, the calculation of the net clinical benefit may serve to inform clinical decision making, suggesting that sGC stimulators offer no benefits and could potentially be harmful.

\section{Limitations}

Our study is constrained by the limitations of the included studies. Patient-level data were missing to measure the impact of non-compliance on overall clinical outcomes. Long term follow-up data was lacking in more than half of the included studies, limiting our ability to calculate their predictive effects. Some studies focused on nonclinical primary outcomes (pro-BNP, PAP) neglecting a significant amount of clinical complications such as myocardial infarction and mortality, reducing the precision of estimated complications. Due to the paucity of long-term follow-up data, it is unclear if these results could be extrapolated to patients with HFpEF. The ongoing DYNAMIC study might shed more light on the efficacy of sGC in patients with $\mathrm{HFpEF}^{[15]}$.

It can also be argued that the assessment of the efficacy and safety of the sGC stimulators is a bivariate exercise, and summarizing it in a unidimensional variable (net clinical benefit) could be misleading. For example, a large number of relatively minor episodes of hypotension versus a small improvement in HF-related hospitalization rate may lead to a negative calculated Net Clinical Benefit (NCB). Still, given the vast disparity between the impact on the quality of life between an episode of hypotension versus HF-related hospitalization, it may falsely undervalue the benefit of therapy. Therefore, the NCB value should preferably be interpreted in the context of the nature of both adverse and beneficial events, without committing to value judgment. That being said, in our case, we found no significant beneficial effect of sGC stimulators and a higher incidence of adverse effects rendering this a moot point.

\section{CONCLUSION}

Vericiguat and riociguat offer no additional benefits to current guideline-based medical therapy in terms of reducing the incidence of hospitalization or mortality in patients with HFpEF or HFrEF. Further larger-scale studies are needed to validate these findings.

\section{ARTICLE HIGHLIGHTS}

\section{Research background}

Despite treatment with traditional pharmacologic management, patients with heart failure (HF) have a dismal prognosis, with approximately 1 million HF-related hospitalizations (HHF) occurring annually, accounting for over 6.5 million hospital days and $\$ 37.2$ billion each year. 


\section{Research motivation}

This has led researchers to study the efficacy of alternate drugs in preventing HF exacerbations, which include soluble guanylate cyclase (sGC) stimulators vericiguat and riociguat. Multiple clinical trials have attempted to explore the utility of vericiguat and riociguat in patients with HF. However, there a lack of large scale studies to determine the true merits of sGC stimulators in patients with HF.

\section{Research objectives}

Therefore, we performed this meta-analysis to determine the efficacy and safety of sGC stimulators in HF patients.

\section{Research methods}

The MEDLINE (PubMed, Ovid), Embase, Clinicaltrials.org and Cochrane databases were queried with various combinations of medical subject headings $(\mathrm{MeSH})$ to identify relevant articles. All randomized control trials (RCT) until March 31, 2020, comparing the safety and efficacy of sGC in HF were evaluated for inclusion. The primary efficacy endpoint was a composite of the first hospitalization for HF and death from cardiovascular causes. The secondary efficacy endpoints were the components of the primary outcome, total HF-related hospitalizations, cardiovascular and all-cause mortality. The statistical analysis was performed using the Cochran-Mantel-Haenszel test on a random-effect model to calculate relative risk (RR) for the dichotomous outcomes of RCTs. The overall quality of the included RCTs was high.

\section{Research results}

Six RCTs comprising 5604 patients (2801 sGC stimulator and 2803 placebo) were included. The primary endpoint (a composite of cardiovascular mortality and first HFrelated hospitalization) was reduced in patients receiving sGC stimulators compared to placebo [RR $0.92,95 \%$ confidence interval (CI): 0.85-0.99, $P=0.02]$. The incidence of total HF-related hospitalizations were also lower in sGC group (RR 0.91, 95\% CI: 0.86$0.96, P=0.0009)$, however, sGC stimulators had no impact on all-cause and cardiovascular mortality (RR 0.96, 95\% CI: 0.86-1.07, $P=0.45$ ) and (RR 0.94, 95\%CI: 0.83-1.06, $P=0.29$ ), respectively. The overall safety endpoints (composite of hypotension and syncope) were also identical between the two groups (RR 1.50, 95\% CI: $0.93-2.42, P=0.10$ ). For the primary composite endpoint, the number needed to treat was 35 , the number needed to harm was -44 and the overall net clinical benefit was -9 .

\section{Research conclusions}

Data published in literature revealed no additional benefits to guideline-based medical therapy in reducing incidence of HF hospitalization and mortality with sGC stimulator use. Large scale studies are required to determine the efficacy of sGC stimulators in patients with HF.

\section{Research perspectives}

As it is unclear whether sGC stimulators have any additional benefit in improving the prognosis of HF patients due to a lack of substantial research, large scale studies are needed to determine their efficacy in reducing HF related hospitalization rates.

\section{ACKNOWLEDGEMENTS}

We sincerely thank Dr. Smith D, and Dr. Eisenstaedt R for providing research opportunities and resources in the institute.

\section{REFERENCES}

1 Benjamin EJ, Virani SS, Callaway CW, Chamberlain AM, Chang AR, Cheng S, Chiuve SE, Cushman M, Delling FN, Deo R, de Ferranti SD, Ferguson JF, Fornage M, Gillespie C, Isasi CR, Jiménez MC, Jordan LC, Judd SE, Lackland D, Lichtman JH, Lisabeth L, Liu S, Longenecker CT, Lutsey PL, Mackey JS, Matchar DB, Matsushita K, Mussolino ME, Nasir K, O'Flaherty M, Palaniappan LP, Pandey A, Pandey DK, Reeves MJ, Ritchey MD, Rodriguez CJ, Roth GA, Rosamond WD, Sampson UKA, Satou GM, Shah SH, Spartano NL, Tirschwell DL, Tsao CW, Voeks JH, Willey JZ, Wilkins JT, Wu JH, Alger HM, Wong SS, Muntner P; 
American Heart Association Council on Epidemiology and Prevention Statistics Committee and Stroke Statistics Subcommittee. Heart Disease and Stroke Statistics-2018 Update: A Report From the American Heart Association. Circulation 2018; 137: e67-e492 [PMID: 29386200 DOI: 10.1161/CIR.0000000000000558]

2 McMurray JJ, Adamopoulos S, Anker SD, Auricchio A, Böhm M, Dickstein K, Falk V, Filippatos G, Fonseca C, Gomez-Sanchez MA, Jaarsma T, Køber L, Lip GY, Maggioni AP, Parkhomenko A, Pieske BM, Popescu BA, Rønnevik PK, Rutten FH, Schwitter J, Seferovic P, Stepinska J, Trindade PT, Voors AA, Zannad F, Zeiher A; Task Force for the Diagnosis and Treatment of Acute and Chronic Heart Failure 2012 of the European Society of Cardiology, Bax JJ, Baumgartner H, Ceconi C, Dean V, Deaton C, Fagard R, FunckBrentano C, Hasdai D, Hoes A, Kirchhof P, Knuuti J, Kolh P, McDonagh T, Moulin C, Popescu BA, Reiner Z, Sechtem U, Sirnes PA, Tendera M, Torbicki A, Vahanian A, Windecker S, McDonagh T, Sechtem U, Bonet LA, Avraamides P, Ben Lamin HA, Brignole M, Coca A, Cowburn P, Dargie H, Elliott P, Flachskampf FA, Guida GF, Hardman S, Iung B, Merkely B, Mueller C, Nanas JN, Nielsen OW, Orn S, Parissis JT, Ponikowski P; ESC Committee for Practice Guidelines. ESC guidelines for the diagnosis and treatment of acute and chronic heart failure 2012: The Task Force for the Diagnosis and Treatment of Acute and Chronic Heart Failure 2012 of the European Society of Cardiology. Developed in collaboration with the Heart Failure Association (HFA) of the ESC. Eur J Heart Fail 2012; 14: 803-869 [PMID: 22828712 DOI: 10.1093/eurjhf/hfs 105]

3 Armstrong PW, Pieske B, Anstrom KJ, Ezekowitz J, Hernandez AF, Butler J, Lam CSP, Ponikowski P, Voors AA, Jia G, McNulty SE, Patel MJ, Roessig L, Koglin J, O'Connor CM; VICTORIA Study Group. Vericiguat in Patients with Heart Failure and Reduced Ejection Fraction. N Engl J Med 2020; 382: 18831893 [PMID: 32222134 DOI: 10.1056/NEJMoa1915928]

4 Mogensen UM, Gong J, Jhund PS, Shen L, Køber L, Desai AS, Lefkowitz MP, Packer M, Rouleau JL, Solomon SD, Claggett BL, Swedberg K, Zile MR, Mueller-Velten G, McMurray JJV. Effect of sacubitril/valsartan on recurrent events in the Prospective comparison of ARNI with ACEI to Determine Impact on Global Mortality and morbidity in Heart Failure trial (PARADIGM-HF). Eur J Heart Fail 2018; 20: 760-768 [PMID: 29431251 DOI: 10.1002/ejhf.1139]

5 McMurray JJ, Packer M, Desai AS, Gong J, Lefkowitz MP, Rizkala AR, Rouleau JL, Shi VC, Solomon SD, Swedberg K, Zile MR; PARADIGM-HF Investigators and Committees. Angiotensin-neprilysin inhibition versus enalapril in heart failure. $N$ Engl J Med 2014; 371: 993-1004 [PMID: 25176015 DOI: 10.1056/NEJMoa1409077]

6 Erdmann E, Semigran MJ, Nieminen MS, Gheorghiade M, Agrawal R, Mitrovic V, Mebazaa A. Cinaciguat, a soluble guanylate cyclase activator, unloads the heart but also causes hypotension in acute decompensated heart failure. Eur Heart J 2013; 34: 57-67 [PMID: 22778174 DOI: 10.1093/eurheartj/ehs 196]

7 Follmann M, Ackerstaff J, Redlich G, Wunder F, Lang D, Kern A, Fey P, Griebenow N, Kroh W, BeckerPelster EM, Kretschmer A, Geiss V, Li V, Straub A, Mittendorf J, Jautelat R, Schirok H, Schlemmer KH, Lustig K, Gerisch M, Knorr A, Tinel H, Mondritzki T, Trübel H, Sandner P, Stasch JP. Discovery of the Soluble Guanylate Cyclase Stimulator Vericiguat (BAY 1021189) for the Treatment of Chronic Heart Failure. J Med Chem 2017; 60: 5146-5161 [PMID: 28557445 DOI: 10.1021/acs.jmedchem.7b00449]

8 Bonderman D, Ghio S, Felix SB, Ghofrani HA, Michelakis E, Mitrovic V, Oudiz RJ, Boateng F, Scalise AV, Roessig L, Semigran MJ; Left Ventricular Systolic Dysfunction Associated With Pulmonary Hypertension Riociguat Trial (LEPHT) Study Group. Riociguat for patients with pulmonary hypertension caused by systolic left ventricular dysfunction: a phase IIb double-blind, randomized, placebo-controlled, dose-ranging hemodynamic study. Circulation 2013; 128: 502-511 [PMID: 23775260 DOI: 10.1161/CIRCULATIONAHA.113.001458]

9 Stasch JP, Pacher P, Evgenov OV. Soluble guanylate cyclase as an emerging therapeutic target in cardiopulmonary disease. Circulation 2011; 123: 2263-2273 [PMID: 21606405 DOI: 10.1161/CIRCULATIONAHA.110.981738]

10 Pieske B, Maggioni AP, Lam CSP, Pieske-Kraigher E, Filippatos G, Butler J, Ponikowski P, Shah SJ, Solomon SD, Scalise AV, Mueller K, Roessig L, Gheorghiade M. Vericiguat in patients with worsening chronic heart failure and preserved ejection fraction: results of the SOluble guanylate Cyclase stimulatoR in heArT failurE patientS with PRESERVED EF (SOCRATES-PRESERVED) study. Eur Heart J 2017; 38 : 1119-1127 [PMID: 28369340 DOI: 10.1093/eurheartj/ehw593]

11 Gheorghiade M, Greene SJ, Butler J, Filippatos G, Lam CS, Maggioni AP, Ponikowski P, Shah SJ, Solomon SD, Kraigher-Krainer E, Samano ET, Müller K, Roessig L, Pieske B; SOCRATES-REDUCED Investigators and Coordinators. Effect of Vericiguat, a Soluble Guanylate Cyclase Stimulator, on Natriuretic Peptide Levels in Patients With Worsening Chronic Heart Failure and Reduced Ejection Fraction: The SOCRATES-REDUCED Randomized Trial. JAMA 2015; 314: 2251-2262 [PMID: 26547357 DOI: 10.1001/jama.2015.15734]

12 Rosenkranz S, Ghofrani HA, Beghetti M, Ivy D, Frey R, Fritsch A, Weimann G, Saleh S, Apitz C. Riociguat for pulmonary arterial hypertension associated with congenital heart disease. Heart 2015; 101: 1792-1799 [PMID: 26135803 DOI: 10.1136/heartjnl-2015-307832]

13 Bonderman D, Pretsch I, Steringer-Mascherbauer R, Jansa P, Rosenkranz S, Tufaro C, Bojic A, Lam CSP, Frey R, Ochan Kilama M, Unger S, Roessig L, Lang IM. Acute hemodynamic effects of riociguat in patients with pulmonary hypertension associated with diastolic heart failure (DILATE-1): a randomized, doubleblind, placebo-controlled, single-dose study. Chest 2014; 146: 1274-1285 [PMID: 24991733 DOI: 10.1378/chest.14-0106]

14 Sterne JA, Sutton AJ, Ioannidis JP, Terrin N, Jones DR, Lau J, Carpenter J, Rücker G, Harbord RM, Schmid CH, Tetzlaff J, Deeks JJ, Peters J, Macaskill P, Schwarzer G, Duval S, Altman DG, Moher D, Higgins JP. Recommendations for examining and interpreting funnel plot asymmetry in meta-analyses of randomised controlled trials. BMJ 2011; 343: d4002 [PMID: 21784880 DOI: 10.1136/bmj.d4002]

15 Mascherbauer J, Grünig E, Halank M, Hohenforst-Schmidt W, Kammerlander AA, Pretsch I, SteringerMascherbauer R, Ulrich S, Lang IM, Wargenau M, Frey R, Bonderman D. Evaluation of the pharmacoDYNAMIC effects of riociguat in subjects with pulmonary hypertension and heart failure with 
Ullah W et al. Safety and efficacy of sGC stimulators in heart failure

preserved ejection fraction : Study protocol for a randomized controlled trial. Wien Klin Wochenschr 2016; 128: 882-889 [PMID: 27590259 DOI: 10.1007/s00508-016-1068-8] 


\section{DS \\ Baishideng ${ }^{\circledR}$}

Published by Baishideng Publishing Group Inc

7041 Koll Center Parkway, Suite 160, Pleasanton, CA 94566, USA

Telephone: +1-925-3991568

E-mail: bpgoffice@wignet.com

Help Desk: https:/ /www.f6publishing.com/helpdesk

https://www.wjgnet.com

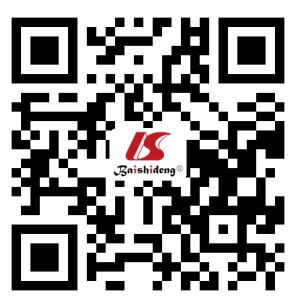

